\title{
Análisis lírico en Luis Cernuda y Federico García Lorca, adscritos a la heteronomía temática de la generación del 27
}

\author{
Lyrical Analysis in Luis Cernuda and Federico Garcia Lorca, Attached to the Thematic Heteronomy \\ of the Generation of 27
}

\author{
Jesús Miguel Delgado Del Aguila ${ }^{1}$ \\ https://orcid.org/0000-0002-2633-8101
}

\begin{abstract}
Resumen: Este artículo realiza un análisis de los poemas de Luis Cernuda y Federico García Lorca que pertenecen a la generación del 27 , un grupo de escritores españoles que surgió a inicios del siglo XX, que se distingue por la inmediata accesibilidad que suscitan para los lectores de su época, ya que adaptaron adecuadamente la poética del modernismo literario, que se opuso al determinismo y el estructuralismo estáticos del lenguaje como expresión. El propósito de este estudio es percibir las variantes, producto de la contrastación de categorías, que se patentizan a partir de la extracción de los tópicos propios de los versos, para después corroborar con los paradigmas inmanentes del surrealismo, que están expuestos en los manifiestos de André Bretón, junto con la cosmovisión que adoptan Octavio Paz y Paul Illie.
\end{abstract}

Palabras clave: generación del 27; surrealismo; análisis lírico; poesía ibérica; cosmovisión.

\begin{abstract}
This paper analyzes the poems of Luis Cernuda and Federico Garcia Lorca that belong to the generation of 27, a group of Spanish writers that emerged in the early twentieth century, which is distinguished by the immediate accessibility that arise for the readers of its epoch, since they adequately adapted the poetics of literary modernism, which strongly opposed to static determinism and structuralism of language as expression. The purpose of this study is to perceive the variants, product of the contrast of categories, which are patented from the extraction of the topics typical of the verses, and then corroborate with the immanent paradigms of surrealism, which are exposed in the manifestos of Andre Breton, along with the worldview adopted by Octavio Paz and Paul Illie.
\end{abstract}

Keywords: generation of 27; surrealism; lyrical analysis; Iberian poetry; worldview.

\section{Introducción}

Para el propósito de este artículo, antes de abordar los lineamientos que facilitarán la comprensión de la poesía de la generación del 27, es primordial retomar los planteamientos que consideraron los modernistas en cuanto que el arte no debe ser un objeto estático con sus respectivos componentes basados en una lógica tradicional y un cientificismo que pretenden universalizar la realidad. Ante ello, será de utilidad el texto de Antonio Machado, titulado "Juan de Mairena" (2010), en el que se precisa que tendrá que reformularse el modo de apreciación en torno al arte; específicamente, en la poesía, que tendrá que dejar de regirse con rigurosidad de su composición lógica y estable para adquirir un estilo estético autónomo que permita dirigirse a un público apto para captar la sensibilidad lírica a partir del tratamiento de los temas. Se buscará abordar el tópico del ser en cuanto su complejidad inherente y contradictoria. 
Luego de este apartado, explicaré las peculiaridades que constituyen la totalidad de la generación del 27. Para ello, será necesario corroborar las instancias del lenguaje, como la utilidad de la aliteración y la metáfora como figuras retóricas. Confrontaré con propuestas metodológicas desarrolladas por Stefano Arduini en Prolegómenos a una teoría general de las figuras (2000), Jacques Lacan en El seminario. Libro 5. Las formaciones del inconsciente (1998) y Marco Fabio Quintiliano en Instituciones oratorias (1887), con el propósito de cerciorarse del sentido que se les otorgará a los poetas de ese contexto.

De igual manera, la heteronomía de los tópicos de los poetas de la generación del 27 será abordada, con el objetivo de orientarla hacia la premisa de que hubo un interés sociopolítico y humano, que predominó sobre la construcción lírica. En ese sentido, el compromiso del artista con su sociedad prevalece, el cual se comprobará con los poemas de Luis Cernuda y Federico García Lorca, quienes se caracterizan por revelar en sus versos discursos implícitos que se dirigen a la preservación del rol que debe adoptar todo ciudadano frente a los percances de la vida, ya sea de forma individual o colectiva.

Para finalizar, se fundamentará el surrealismo, en función de lo trabajado por los manifiestos de André Bretón, junto con los planteamientos elaborados por Octavio Paz y Paul Illie. Una vez determinada su definición, se comprenderá el objetivo de este movimiento artístico y se extrapolarán sus variantes para el análisis de los poemas de Luis Cernuda y Federico García Lorca. Ceñirse a estos poetas será eficaz si se supone la previa consideración de los tropos, debido a que la enunciación de la generación del 27 exige tener en cuenta la realidad desde una percepción totalmente diferente: múltiples expresiones ilógicas, requerimiento de conocimientos culturales y posición de activismo político.

\section{Desarrollo}

\subsection{Concepción del poeta antes de la generación del 27: propuesta contextual de Antonio Machado a partir del distanciamiento del modernismo}

Considerando la poética de "Juan de Mairena" (2010, p. 1), Antonio Machado argumenta que las artes tienen la expectativa de convertirse en productos permanentes e ilimitados. Esto acontece con las artes del tiempo, como la música y la poesía. Su estrategia empleada es la distorsión cronológica desde la representación de estadios caracterizados por el esteticismo y divididos por tópicos que se desligan del conservadurismo tradicional, con referencia al autor. Es lo que él atribuye como la lírica en particular, en función de la lógica rimada (Machado, 2010, p. 3).

El poeta hace uso de múltiples recursos para destacar esa construcción versátil: cantidad, medida, acentuación, pausas, rima e imágenes. Estos elementos temporales pretenden evadir el transcurrir inmanente y sensible de la realidad. Por eso, la necesidad de plasmar un modo auténtico de disuadir el mundo suscita retomar la creatividad de un pensamiento analítico, por el que la espontaneidad del momento y la vida humana obtienen relevancia poética. Es más, se trata de una voluntad del manipulador, quien elige el fonograma lógicamente más afín a las circunstancias.

La lírica moderna del siglo XX es identificable por sus contradicciones. Sus principales exponentes fueron Antonio Machado, Juan Ramón Jiménez, Jorge Guillén, García Lorca, Rafael Alberti, Gerardo Diego, Dámaso Alonso y Vicente Aleixandre. En España, se caracterizó por ser oscura y esotérica. La filiación con la tradición nacional no repercutió solo en poetas españoles como Góngora, sino también a la poesía popular, como se aprecia en los romances (Friedrich, 1974, p. 190). Según Friedrich (1974, p. 186), en la lírica española, se encuentran dos tendencias: la formalmente libre y alógica y la intelectual. La primera se vincula con lo onírico. En esta, la deformación de 
las imágenes se fija en las figuras consolidadas por el yo poético (subjetivamente, equivale a la fantasía creadora del surrealismo). La segunda tendencia se diferencia por el interés en no emular los patrones anteriores, sino de reformularlos desde enfoques heterogéneos. Al respecto, Friedrich confirmó lo siguiente: "No existe tal multiplicidad: existen solo matices y variantes que atestiguan las numerosas posibilidades de la poesía contemporánea, pero que no son substanciales para el juicio de su estructura estilística" (1974, p. 185).

Hugo Friedrich define unos conceptos indispensables para comprender esta forma artística en su libro Estructura de la lírica moderna, que son el estilo, la unidad y la originalidad.

Primero, el estilo es el principal patrón que permite regular y delimitar las expresiones artísticas en un poema (Friedrich, 1974, p. 195). Asimismo, se trata de la extrapolación de un lenguaje en su ipseidad, que toma como referencia el resultado de lo real y lo cotidiano. Importa cerciorarse cómo se ha proyectado esa percepción durante la manifestación de la poesía española, pues con la lírica anterior hubo un balance entre fondo y forma. Entretanto, en la poesía moderna, se ha sustituido por el predominio de esta última, con sus inquietudes, sus incoherencias y sus rarezas: el estilo inusual capta la atención por antonomasia. Verbigracia, García Lorca domina la lírica moderna: incorpora el anonimato. También, se encuentran otros aportes técnicos, como la aparición y la aplicación del fundido y la metáfora; es más, es reconocible una hostilidad a la frase, cuya exhibición se infiere del fragmentarismo (Friedrich, 1974, p. 199). Otro recurso es el del silencio dentro de los versos, que poéticamente connota la interioridad humana transmitida al lector.

Segundo, la unidad es el conjunto organizado de palabras y esquemas que constituyen un poema, estructural y sintácticamente. Esta evita imbricar el verso con la prosa, lo cómico con lo trágico, lo elevado con lo vulgar. Se rige a través de un persistente configurador de la poética constructivista. En torno a ello, Friedrich indica que "desde Poe y Baudelaire, los líricos desarrollan una reflexión poético-teórica que avanza paralelamente a su propia obra" (1974, p. 190). Muchas veces, es insoslayable percibir cómo se determina la arquitectura de cada estrofa o verso, ya que estos comprenden el principio matemático o la síntesis de un gran cúmulo de tópicos inabarcables. No obstante, estas bases y fuentes, como las asume Friedrich (1974, p. 184), son postulados supeditados a la lírica europea del siglo pasado.

Tercero, la originalidad es una cuestión de calidad inherente de cada ser humano, en la que se prioriza su libertad en el ámbito artístico. Friedrich (1974, p. 212) la adopta como poder de creación con respecto a la imaginación imperante, debido a que para él el lírico pensador cuenta con una ideología inminente para la creación del poema. Un modo de representar la originalidad es anulando las bases anteriores para proponer algo autónomo: una renovación. A ello, Friedrich (1974, p. 263) añade que en la poesía actual esta imaginación dictadora origina transformaciones y destrucciones del mundo de la realidad.

Para Hugo Friedrich, las nuevas adquisiciones artísticas se sintetizan en la siguiente fundamentación: "Para definir un poema moderno es preciso detenerse mucho más en el estudio de su técnica expresiva que en el de sus contenidos, su argumento y sus temas" (1974, p. 194). Es decir, se relaciona con el avance técnico de las construcciones en los poemas, sin que se percate un aporte notorio en el nuevo lenguaje del siglo XX, porque la lírica de la tradición española ya tiene múltiples experimentaciones formales que posteriormente fueron insuperables. Entonces, ¿cuál es el nuevo lenguaje? Friedrich precisa el término como "el concepto de 'lenguaje nuevo' solo se precisa un poco allí donde acentúa su intención agresiva. Al romper con lo habitual, se convierte en un shock para el lector" (1974, p. 197). Por ende, se trata de la dificultad sintáctica y semántica, la misma que requiere una reformulación del texto por un lenguaje comprensible, con el que lo ridículo y lo absurdo adoptan similar relevancia que las nuevas realidades de la civilización. En ese sentido, se 
revela su pretensión por avalar la ambigüedad, con el objetivo de que el lenguaje poético se sobreponga al coloquial, con mayor frecuencia que lo hizo la poesía anterior (Friedrich, 1974, p. 203). De ello, se infiere que prevalece una consuetudinaria adhesión a la búsqueda y la renovación del estilo por medio de un nuevo lenguaje.

Partiendo de una idea panorámica, se infiere que la intención del texto de Machado (2010, p. 2) es fundamentar que la esencial heterogeneidad del ser consiste en su otredad: su sustancia única. Se critica la labor cientificista, ya que esta se exhibe como un infinito en tanto que sus objetivos se muestran insostenibles y ambiguos. De ello, solo es posible comprender una apariencia variable de la realidad, mas no su totalidad (Machado, 2010, p. 7). El tiempo que se presenta es anacrónico. Con ello, su propósito de direccionar una idea acerca de la eternidad se reduce a la estructuración del tiempo desde las experiencias vividas. No es el fin adquirir un conocimiento: el poeta no anhela saber nada, no siente la necesidad de asentar nociones que más adelante, con sus juicios analíticos, transmutará en razonamientos.

La poesía de ese período se rige de las concepciones desarrolladas por Ortega y Gasset con su texto La deshumanización del arte (1925). Desde allí, este filósofo establece una conexión entre la realidad ontológica y la obra de arte. Por ejemplo, también señalaba que "estilizar es deformar la realidad, desrealizar. Estilización implica deshumanización” (Friedrich, 1974, p. 219). A partir de ello, Friedrich entiende que la deshumanización es la claudicación de los estados naturales y el cambio jerárquico entre el objeto y el hombre, que son invertidos para que este último adopte un rol ínfimo. Se asocian temas que abordan la degradación, la perversión, el desamor, la soledad, la maldad, la oscuridad, el hermetismo, la anormalidad, la incoherencia, lo humorístico, lo transgresor, etc. Se insertan dentro de la tradición de los poemas modernos, con la finalidad de erigir múltiples componentes ambiguos que destacan ese efecto inusitado, que distinguirá a esta nueva tradición de la anterior. Más adelante, Friedrich confirma lo siguiente: "La lírica contemporánea observa actitudes muy diversas respecto al mundo, pero el resultado es siempre el mismo: desvalorización de la realidad" (1974, p. 255).

Asimismo, el tiempo y la poética de Juan de Mairena se adhieren por su construcción rigurosa, formal y habitual. Prevalece la predominancia por esta trabazón (la forma), más que por el contenido (el fondo). Igualmente, esta es una manera de distanciarse de la tradición literaria, puesto que se irrumpe la estratificación consolidada al postular otras. El tiempo con la poética esencial parte del tópico de que esta ha perdido su significación. Así como este, el espacio es puro ser que no es: la nada (Machado, 2010, p. 8). Desde allí, este parámetro se asocia más con la emoción humana que con la representación de la realidad. Esa presentación temporal sugiere un devenir, que resulta enigmático: individualiza las concepciones genéricas. Para Machado, esto es válido por lo siguiente: "Las coloca en el tiempo, en un pasado vivo, donde el poeta pretende intuirlas como objetos únicos, las rememora o evoca" (2010, p. 4).

La propensión que se efectúa entre la poética de Mairena y la modernidad adopta un sentimiento auténtico. Machado (2010, pp. 5-6) detecta cómo se rigió el barroco (comprendió el culteranismo y el conceptismo) en relación con una nueva forma de suscitar mayor esteticismo receptivo, debido a las manifestaciones constantes de las apariencias; por ejemplo, el barroco literario español se caracterizó por las posesiones y las carencias. Primero, se afilia con la expresión indirecta, perifrástica, como si tuviera un valor estético. Además, es considerable por lo artificioso, el desdeño de lo natural, lo negación a lo artificial, lo supersticioso y lo aristocrático. Segundo, se exime de temporalidad y gracia, por las que se exterioriza un descuido por la intuición y la ignorancia de las dificultades reales. Los vasos comunicantes que se establecen con el modernismo se produjeron por la existencia de una reacción contra la mediocridad y el desinterés por el romanticismo. Se postulan como principios el esteticismo (arte para minorías), la aristocracia del espíritu (evocaciones cultas, 
sensualidad enfermiza), el refinamiento de las formas (renovación rítmica, delicadeza verbal, efectos sonoros y plásticos) y un abordaje pictórico de América.

\subsection{La generación del 27}

En Estudios sobre poesía española contemporánea (1957), el autor sostiene que la nueva percepción de España se mantiene en posturas y expresiones modernistas, con las que la poesía adopta un valor autónomo. Por eso, se recurre mayormente a la ambigüedad o la paradoja. En torno a ello, Luis Cernuda señala lo siguiente:

La influencia de Góngora, combinada con la actitud clasicista, tuvo otra consecuencia, que es la reaparición de la métrica (octosílabos, endecasílabos, etc.), y de las estrofas (soneto en su forma ortodoxa, letrillas, romances, octavas reales, etc.) tradicionales, metros y estrofas que el modernismo puso en fuga (Matas, Martínez \& Trabado, 2005, p. 29).

Por ende, la generación del 27 es producto de la decadencia técnica superrealista, aunque la poesía no requiera ningún lenguaje poético específico: no existe palabra que se excluya. Cualquier intervención discursiva completará el sentido de la enunciación (Guillén, 1992, p. 195). De esa forma, equivale a una expresión y una dicción adicional. La imagen que patentizan desarrolla su propio valor. Sus temas son más directos y efectivos. Un tropo recurrente es la aliteración, que se distingue por la repetición de sonidos en un determinado verso o un conjunto de ellos. Este rasgo otorgará mayor dramatismo a la expresión del poema.

Cernuda prioriza la intención que tienen los poetas de la generación del 27: la articulación de la metáfora, que se define como el procedimiento para establecer un nuevo significado por medio de operaciones lógicas (Lacan, 1998, p. 179), basadas en las analogías, las comparaciones y las semejanzas (Quintiliano, 1887, p. 68). Según Stefano Arduini (2000, pp. 81-84), a través de esa alteración característica, se logrará la construcción de una innovadora manera de percibir el mundo. El modo de presentar esta figura retórica debe ser estéticamente aceptable para el lector. Por ello, es insoslayable que se utilicen las palabras suficientes para conseguir precisión y criterio, tal como lo confirma Aristóteles (1990, pp. 490-494), ya que estas se dirigen a un público que conoce y está conforme con los referentes reales que se exponen en ese discurso (Fontanier, 1977, p. 99). Por otro lado, se considera la función efectiva y musical (íntima y delicada) de estos poetas. Esa peculiaridad se aprecia en el poema "La luz" de La destrucción o el amor (1935) de Vicente Aleixandre: "Amorosa forma que siento respirar" (verso 2. ${ }^{\circ}$ ), "una música" (verso 3. ${ }^{\circ}$ ), "arpas angélicas" (verso $4 .^{\circ}$ ) y "rumor de unos mundos" (verso $5 .^{\circ}$ ). Se busca explicar lo subjetivo, a pesar de que este se exhibe con diversidad y extensión, pero serán la escritura y la objetividad una limitación para sintetizar y escoger lo más eximio de ese estado anímico. En el $10 .^{\circ}$ verso, se observan dos entidades, quien enuncia y a quien se pretende ubicar: "Dime, dime quién es, quién me llama, quién me dice, quién me clama". Aparte de la metáfora, otra figura retórica es la antítesis. Se trata de una contradicción que se manifiesta con cercanía o lejanía a lo largo del poema (Arduini, 2000, p. 121). Para obtener ese efecto estético, se le designan dos atribuciones semánticas a cada elemento y estas serán ambivalentes por su propia esencia: color, magnitud, peso, etc., como sucede al oponer blanco (día) con negro (noche). En el 1. ${ }^{\text {er }}$ verso, se muestra lo siguiente: "Esa llegada de la luz que descansa en la frente", en el que la luz representa la esperanza y la vida. Entretanto, la oscuridad se respalda del pesimismo y la muerte. De forma similar, acontece en el verso 19. ${ }^{\circ}$ " "De los cuerpos que existen, de las almas que existen". 


\subsection{Análisis temático de poemarios de la generación del 27}

En La voz a ti debida (1933) de Pedro Salinas, es predominante el tópico de la trascendencia que se configura a partir de una instancia que procura instalarse diacrónicamente en una área determinada de la conciencia humana, como se localiza en los versos $5 .^{\circ}$ y $6 .^{\circ}$ : "Detrás, detrás, más allá / Por detrás de ti te busco". Por otro lado, Juan Marichal (1993, p. 33) argumenta que es característica en la generación del 27 hallar el contraste entre la vida eterna con la disminución a la muerte. Esa peculiaridad más compleja se evidencia explícitamente en los versos del $18 .^{\circ}$ al $20 .^{\circ}$ : "Por encontrarte, dejar / de vivir en ti, y en mí, / y en los otros". El yo poético siente igual que otros. Se vale de una carencia o una alienación, la cual irá implicándose en el poema de su literatura y su cultura inmanentes. Un tono poético y dramático comprende esa consuetudinaria alusión existencialista a la vida: "Como si fuese morir" (verso 101. ${ }^{\circ}$ ). Para Jorge Guillén (1992, p. 184), esa postura se instaura no tan solo de una manera dinámica, pues esta requiere expresar paradoja y determinismo que revela en su máxima representación la noción de vida con un rasgo experimental. A la vez, añade que lo religioso resulta obviado, ya que es para la generación más importante abarcar los problemas humanos: amor, universo, destino o muerte. Juan Cano Ballesta $(1972$, p. 9) planteó que las guerras y las derrotas provocaron un efecto negativo en la sociedad española. En cambio, las victorias configuraron la euforia esperanzadora de revolución. Ese rasgo comprometido e iconoclasta se transformó en un pretexto que devenía la responsabilidad o la irresponsabilidad del artista (Real Ramos, 1990, p. 169). Por el contrario, otro es el enfoque que se proporciona en La voz a ti debida; por ejemplo, al expresar "Detrás, más allá / También detrás, más atrás" (versos $86 .^{\circ}$ y $87 .{ }^{\circ}$ ) no se pretende enunciar un mensaje de alteración, sino manifestar la forma de construir superficialmente un proyecto poético, así sea con la figura retórica de la reiteración.

En la generación del 27, el lenguaje es especial. César Real Ramos (1990, p. 168) lo considera como apriorísticamente bello y estético. No obstante, prevalece una intención de propagar un modo de representación, uno solo, tal como se aprecia en los versos $53 .^{\circ}$ y $54 .^{\circ}$ de "Salvación de la primavera”, del poemario Cántico (1928) de Jorge Guillén: “¡Oh realidad, por fin / Real, en aparición!”; luego, en el verso 48. : "En que el ser llega a ser!"; más adelante, en los versos $51 .^{\circ}$ y $52 .^{\circ}$ : "Aquí está: la verdad / Se revela y nos crea". En esas instancias, se identifica el modo de abordar la realidad. Este tipo de poesía, que tiende a la modificación por la rebeldía de los escritores de España, se asume porque perciben su país en un estado de descomposición ética, territorial y sociopolítica. Sin embargo, la generación del 27 logró que se volviera a lo clásico y lo tradicional. Optan por Góngora, lo cual implicaba el recurso de los conceptismos (Real Ramos, 1990, pp. 166-167). Estos son más trabajados cuando se confronta con el tratamiento del tema amoroso: "Alma, fiel a un volumen. / Doble con abandono, / Alma, tu pesadumbre" (versos $19 .^{\circ}$ y $20 .^{\circ}$ ).

Pierre Bourdieu hace referencia a la lucha por el dominio del poder simbólico (Real Ramos, 1990, p. 163). Igualmente, José Ortega y Gasset postula en 1910: "España es el problema, Europa, la solución" (Marichal, 1993, p. 28). Con respecto a la lírica de la generación del 27, se procura saber los criterios que rigen la vida. En los dos primeros versos del poema "Dejadme solo" de Un río, un amor (1929) de Luis Cernuda: "Una verdad es color de ceniza, / Otra verdad es color de planeta", se cuestiona quién es el hombre. Para ello, se revela una taxonomía de verdades y mentiras, unas más intensas o extensas que otras, como en el verso $11 .^{\circ}$, que muestra dos categorías ambivalentes: "La verdad, la mentira". Para Cernuda, nada está enunciado y se trata de un error calificar a un elemento esencial desde una percepción homogénea. Allí está lo primordial de la deshumanización, que se consolida con la libertad en las artes. Por lo tanto, la negación a la religión es un carácter sedicioso. Sobre ello, César Real Ramos planteaba lo siguiente: "Pureza equivale, así, a inhibición, a falta de compromiso" (1990, p. 169). En consecuencia, la realidad se representa tal como es: se manifiestan los sentimientos y hasta lo erótico (sentimiento amoroso, de pérdida por la amada), con búsqueda del neopopularismo, que es equivalente a un retorno a la tradición. 
Juan Cano Ballesta (1972, p. 37) define el arte como lejano de la vida social y política. No conseguirá ser un instrumento adaptable a la propaganda y sus fines didácticos. De ello, el escritor resulta ser el productor; el público, el consumidor estético, teniendo en cuenta que este tipo de lírica no va dirigido hacia las masas: terminará siendo incomprensible para ellas. Para lograr esa exclusividad receptiva, se adopta la configuración de la referencialidad de la creación, la cual es la realidad exterior y es esta la que se evidencia de forma verosímil (Cano Ballesta, 1972, p. 22), aunque eso implica que se transite por la racionalidad o la subjetividad durante el acto de plasmar. En el verso 4. ' del poema "Música cautiva" de Desalación de la quimera (1956) de Luis Cernuda, se anhela oponer estos elementos: "Si están en desacuerdo realidad y deseo". Allí, se muestra cómo el hombre vive en los estados objetivos o subjetivos. En torno a este último, es trabajado desde una perspectiva amorosa, tal como lo describe al iniciar "Música cautiva": "Tus ojos son los ojos de un hombre enamorado" (1. ${ }^{\text {er }}$ verso). En este, predomina la individualidad y el tiempo en que se presenta, con la intención de trascender diacrónicamente y no con sincronía (Marichal, 1993, p. 30).

Biruté Ciplijauskaité (1991, pp. 29-30) sustenta que prevalece una búsqueda por la protesta y la destrucción, las cuales serán contra la tradición del arte como institución. Eso conlleva un placer por la transgresión. Esa idea de ruptura se evidencia en el poema "Razón de lágrimas", de Un río, un amor (1929), en el 1. ${ }^{\text {er }}$ verso: "La noche por ser triste carece de fronteras" o de los versos $3 .^{\circ}$ y 4. ${ }^{\circ}$ : "Rompe los muros débiles. / Avergonzados de blancura". Es notoria la idea de irrupción de limitaciones, propio de la vanguardia y el modernismo. Ciplijauskaité señala que "los autores de la vanguardia juzgan la realidad social según las normas del deseo estético" (1991, p. 31). Con ello, se requiere un nuevo lector/espectador más sofisticado, con una manera de "exorcizar el mal". La sexualidad se muestra como pervertida. Para Ciplijauskaité (1991, p. 33), es un síntoma de la tradición masculina impuesta en la literatura. Por esa razón, en ese poema de Luis Cernuda, la alusión a "los amantes" (verso 6..$^{\circ}$, o la expresión "impulsada por deseos" (verso 8. ${ }^{\circ}$ ) revela la existencia de un "tú", configurado como un espejismo del deseo pérfido del ser humano. Para Cano Ballesta, "la belleza se convierte en categoría central que inspira y regula el ejercicio artístico" (1972, p. 37). A partir de allí, la intención estética es el deseo de crear poéticamente sin ningún tipo de inmediaciones.

Federico García Lorca remite a "San Miguel” de Romancero gitano (1928) en oportunidades heteróclitas: "San Miguel lleno de encajes" (verso 1. ${ }^{\circ}$ ), "San Miguel canta en los vidrios" (verso 9..$^{\circ}$ ), "San Miguel se estaba quieto" (verso 21..$^{\circ}$ y "San Miguel, rey de los globos" (verso 25..$^{\circ}$. No obstante, esto supone que no se trata de un solo sujeto, más bien, se enfoca en una colectividad, un territorio o una entidad fantasmal e irreal. Por ello, es factible referirse a una figura retórica en especial: la personificación. Esta se distingue por unificar y atribuir caracteres inmanentes de los seres humanos a entes no animados, como los animales, los astros, los objetos o las cosas terrenales. Con esta alteración del orden de lo real, suscitan interpretaciones, que radican ficticiamente en mundos posibles pertenecientes a un texto. George Lakoff y Mark Johnson (1995, p. 72) consideran que este tropo brinda sentido a lo inexplicable con una base humana.

Si bien se detecta un compromiso sociopolítico y el interés en la colectividad, también es importante el enfrentamiento con la realidad inherente del individuo y su aceptación. Lo más cercano a la crítica es la predominancia a la negación de creencias teologales, expresiones eróticas como se muestra en los versos $3 .^{\circ}$ y $4 .^{\circ}$ : "Enseña sus bellos muslos / ceñidos por los faroles". Estas implican la adquisición de conocimiento y revelación por medio de la claridad o la exposición liberal de los cuerpos, así como ocurre con el verso 15.': "Morenas por la nostalgia", en el que lo profano colisiona con la religión: lo oscuro o lo moreno simboliza la maldad, el pecado.

Se nota en este poema de Lorca el estudio de la forma, la importancia de la inteligencia y el recurso de la sugestión. Cano Ballesta (1972, p. 14) confirmaba que la única oportunidad para reducir la 
poesía a su esencia era rehabilitando la autonomía de las artes. Se busca una expresión original: lenguaje oscuro, hermético y enigmático. Para Jorge Guillén (1992, p. 185), la literatura significa "lirismo". Por ello, se destaca el empleo de figuras retóricas como canales de interrupción de la realidad tal cual (Cano Ballesta, 1972, p. 31), como se aprecia en los versos $7 .^{\circ}, 11 .^{\circ}$ y $12 .^{\circ}$, respectivamente: "Cólera dulce", "agua colonia" y "lejano de las flores". En estas situaciones, los sentimientos negativos asimilan otra identificación, para ser adaptados con mayor eficacia, con un talante de individualidad singularizada y exaltada en contra de su propia naturaleza.

\subsection{Abordaje surrealista en creación artística de la generación del 27}

El surrealismo es un movimiento artístico que surgió en Francia durante la década de 1920. André Bretón se ciñe de los argumentos psicoanalíticos de Sigmund Freud, signados por la exploración por descubrir los mecanismos del inconsciente y sobrepasar lo real por lo imaginario y lo irracional.

En el primer manifiesto del surrealismo, escrito por Bretón, se observa cómo la tradición se configura desde una forma distante de la realidad, peculiar de un crítico para evaluar su objeto referencial. A ello, se le añade el conocimiento del psicoanálisis, que intenta desarrollar teorías, con Freud, de lo onírico, lo inconsciente, los actos fallidos, el azar y la negación a la ley de la causalidad. Para Octavio Paz, la imagen del sueño es la subversión de la realidad. Por otro lado, considerando el manifiesto, se pretende disputar dos elementos esenciales: el autor creador y el público receptivo. El primero, quien elude la lógica común, se sirve de atacar y transgredir toda sistematización anterior, sin interés de cuestionar estéticas o morales, sino de encontrar y postular particularidades de manera creativa. El público receptivo, que anhela adquirir un saber extratextual innovador (científico, literario, sociológico o psicoanalítico), tiene el propósito de llegar al nivel intelectual y artístico del narrador, ya que se han cerciorado de que el arte surrealista está dirigido a un público limitado. Eso les provoca angustia y desesperación, tal como lo arguye Bretón. Propende el diálogo desnaturalizado por alegar con una escritura inconsciente, o lo que se denomina como automatismo psíquico puro, que no busca una convergencia causal y lógica entre un enlace sintáctico y semántico del lenguaje, para expresar el pensamiento real. Esto es posible porque Bretón se vale de la concepción de que toda imagen es arbitraria, producto de que la mímesis de la realidad es falsa en sí e incompleta.

Considerando el segundo manifiesto de André Bretón, el surrealismo se asemeja al materialismo histórico y moderno por el desarrollo que se vinculó con el contexto de la primera posguerra europea. Esta se acarrea por la crisis espiritual, así es que se realizaron protestas en oposición a un sistema de valores y una cultura que condujeron a la autodestrucción. Con frecuencia, predomina la captación de la coincidencia-realidad originada en un personaje, cuando vive un hecho que le proporciona recuerdos recónditos. Los surrealistas anhelaron la necesidad del cambio en cuestiones humanas que trascendieran el arte. Combinaron lo político, lo religioso y lo poético. Surgieron los movimientos vanguardistas de principios del siglo XX. Por ejemplo, en Francia, fueron los cubistas en las artes plásticas y el movimiento paralelo en la literatura, con exponentes como Guillaume Apollinaire, Pierre Reverdy, Blaise Cendrars, entre otros; en Alemania, del expresionismo literario y plástico; en Italia, el futurismo. El surrealismo entabla relación con el reverso de lo real, porque el sujeto atraviesa por una etapa de adoctrinamiento, en la que el individuo se constituye ideológicamente por el sentimiento, la actitud y la protesta revolucionarios, en función del bien moral democrático. Esta manera de hacer arte tiende a representar, mediante un lenguaje caótico y libre, la vida profunda del subconsciente, lo irracional, lo maravillosamente irreal. Así, le otorga relevancia a la idea de la belleza, tomada del referente de la apariencia de lo real. El surrealismo se diferenció por ser una escisión del dadaísmo y pretender crear un hombre nuevo (Bretón, 1965, pp. 60-62). Recurre a la crueldad y el humor negro, con el fin de irrumpir aspectos de índole sentimental. No son de su interés los patrones de la conducta moral humana y sus manifestaciones, a pesar de ser constructivo. Su labor es equivalente a la de un escritor con un idealismo de compromiso social, 
que parte del marxismo y rechaza toda forma inactiva del hombre, como cuando Bretón critica al escritor burgués, quien no representa una particularidad (proletaria), sino que se basa en el instinto, las vivencias. Así predomina su interés por la acción con soporte científico, en contra del intelecto.

Asimismo, Octavio Paz en su texto "El surrealismo" (1982) menciona que el ser humano tiende a cuestionarse lo instaurado. Eso le permite revelar un interés por transformar, un deseo en sí. Por esa razón, el surrealismo se caracteriza por la ruptura de lo cotidiano, el empleo de la escritura automática (irracional, crítico, espontáneo e inocente), al igual que la atribución semántica proyectada en las acciones y los sentimientos (como en la creencia del azar por ser objetivo y la negación del principio de causalidad, por ser más subjetivo y menos creíble). No solo se trata de un hacer humano y creativo sino de una actitud: el hombre muestra su imagen con la intención de escindir el presente y transmutarlo en una entidad trascendente en el tiempo. Por eso, será rebelde y transgredirá los valores de la civilización racionalista y cristiana, con conciencia de su libertad. Estas actitudes son propicias, ya que en el surrealismo existió un requerimiento por conocer la verdad de la realidad, a causa de que todo origina signos (el lenguaje y el pensamiento son su sustento). Alcanzar un mensaje implícito por medio de la incomprensión semántica que adopta el complejo aparato formal surrealista significa lograr la conjunción del yo con el mundo, como también de lo interno con lo externo. Obtenerlo será conseguir la reconquista de la presencia del ser. La similitud del surrealismo con el amor es la libre voluntad de accionar: el amor exterioriza el modo más culminante de esa pretensión. Por su adquisición, Octavio Paz (1982, pp. 36-45) lo considera óptimo. Es indispensable que no se excluya el dualismo soberano de libertad y destino, debido a que son pautas para referirse a la poesía o la religión de modo distinto. Así como en lo literario, se espera la aceptación del lector en tanto producto artístico. Para el escritor mexicano, la mujer es la correspondencia en el amor. Eso será lo utópico. Retomarlo de otra manera conllevará la irrupción ontológica y la adopción de un ideal antitético.

Paul Illie se ciñe de la poesía como principio en "El surrealismo español como modalidad" (1982) para plantear su estructura interna no tradicional, que se caracteriza por el absurdo lingüístico, las relaciones incongruentes y la desorientación por el yo poético en dirección a un lector, que no está acostumbrado a leer un tipo de poesía sugerente y a la vez autodestructiva, en tanto que irrumpe los sentidos y se le hace imposible comprenderla. Esa irracionalidad para erigir palabras, frases e ideas irracionales proviene de escritores franceses como Sade, Lautréamont y Rimbaud. Además, a esta forma poética innovadora, se le añaden tópicos que no se abordan naturalmente, como al corroborar con el erotismo y el exhibicionismo. A la vez, pretende captar la atención de la clase conservadora, fundada en los valores y la religión. Por eso, Paul Illie (1982, pp. 95-103) asume que en el trasfondo de la poesía prevalece una intención por parte del autor, que se consolida en el contexto en el que vive. Verbigracia, los temas vinculados con la sociedad, así sea por referentes psicológicos, socioeconómicos o históricos, encubren la insatisfacción que se ostenta de modo implícito en la obra lírica, ya que es un principal instrumento de protesta y construcción del nuevo arte. En el caso del surrealismo español, los temas abarcados desde la perspectiva irracional tienden a expresar un contenido crítico basado en el ambiente local y no tanto histórico, si bien se recurre al aparato formal, aunque no de una manera tan ininteligible. Predomina un interés por revelar las necesidades del autor por una determinada época. Un exponente ineludible de este tipo de poesía surrealista española es Juan Ramón Jiménez.

En el poema "Oscuridad completa" de Un río, un amor (1929) de Luis Cernuda, se fundamenta la utilidad artística del surrealismo: "O verter de mis labios vagamente palabras" (verso 6. ${ }^{\circ}$ ), en el que lo irracional (lo absurdo) se instaura a partir de la reciprocidad romántica del ser. Esa exhibición de la escritura automática, producto de la espontaneidad sin transitar por el filtro de la cohesión lingüística, procura representar la realidad como una imagen ilusoria de lo verdadero, tal como se 
evidencia en el 3. ${ }^{\text {er }}$ verso: "Recogiendo la vida su apariencia". Además, esta peculiaridad se expone en el verso 8. : "Palabras de mis sueños", en el que la concordancia se establece por elementos de la realidad y la ficción; y el verso $10 .^{\circ}$ : "De mis sueños copiando nubes sobre la pampa", en el que lo onírico se emplea como herramienta de la creación artística y la manifestación de mundos posibles.

En el poema “¿Son todos felices?” de Un río, un amor, el autor se vale de lo ilógico para reformular la tradición artística. Esto es notorio en el verso 2. : "El patriotismo hacia la patria sin nombre", en el que se observa la idea de suscitar la revolución, el conflicto, el cambio, propio del surrealismo. A continuación, se muestra esa perspectiva ontológica coligada con lo ético: "Abajo pues la virtud, el orden, la miseria; / Abajo todo, todo, excepto la derrota" (versos $6 .^{\circ}$ y $\left.7 .^{\circ}\right)$. Encima, reincide con el contenido temático que revela el $2 .^{\circ}$ verso: la noción de buscar un nuevo orden, una ética adecuada. Para ello, es imprescindible que los sujetos modifiquen sus estados de ánimo y atraviesen una transformación interna de entidades estáticas y rutinarias a dinámicas, con el objetivo de reestructurar los organismos de regimiento del Gobierno y la sociedad.

En el poema "Ruina" de Poeta en Nueva York (1940) de Federico García Lorca, se observa el interés por evadir esa realidad coetánea. Esto es notable en los versos del $28 .^{\circ}$ al $300^{\circ}$ : "Prepara tu esqueleto; / hay que buscar de prisa, amor, de prisa, / nuestro perfil sin sueño". Además, no solo es la postulación de una realidad ficticia alternativa, sino que el yo poético tiene la expectativa de asimilar una utopía, producto de la unión con su ser amado. Por eso, se corrobora con las invocaciones que hace la instancia enunciativa en los versos $22 .^{\circ}, 25 .^{\circ}$ y $27 .{ }^{\circ}$ respectivamente: "Mi mano, amor", "Tú solo y yo quedamos" y "Yo solo y tú quedamos", en los que la mención de la compañía es insoslayable para el desarrollo personal de cada uno. Por otro lado, algo fundamental en García Lorca es mostrar la colisión de la naturaleza: "La lucha de la arena con el agua" (verso 9. ${ }^{\circ}$ ). Es más, recurrirá a un tropo para sugerir una nueva forma de captar la realidad: la metonimia. Esta se caracteriza por aludir a un pensar sobre la base de la contigüidad, es una sustitución por causalidad, una asociación, que tiene una dependencia externa para poder establecerla. En términos de Lacan (1998, p. 15), esta figura retórica permite apreciar que el deseo de uno es el de otro: diferente de la sinécdoque, que se distingue por no relacionarse con su referente; se construye de manera convencional y no necesariamente contará con una concordancia con el mismo objeto, pues su adhesión dependerá del sujeto. Dentro de "Ruina", se observa cómo el color de una entidad remite a dos elementos heteróclitos: "Viajero por su propio torso blanco / ¡Así iba el aire!” (versos 2. ${ }^{\circ}$ y $3 .^{\circ}$ ), en los que el sustantivo expresado es reemplazado por el aire, como en los versos del $4 .^{\circ}$ al $6 . .^{\circ}$ : "Pronto se vio que la luna / era una calavera de caballo / y el aire una manzana oscura". En ese caso, los colores del astro son similares a los de la calavera, aunque, considerando la concepción de mortandad, la fruta oscura revela la filiación con la muerte.

\section{Conclusiones}

Principalmente, se comprendió la cosmovisión signada por el modernismo, que buscó desligarse de los parámetros determinados del arte culto en cuanto su composición estética, como la construcción inamovible de la métrica y la rítmica. En torno a ello, Antonio Machado expresa que fue imprescindible confrontar con temas subjetivos que se derivaban de la conformación del ser como sustancia dinámica y compleja, para que se patentice su proyecto literario, sobre todo, en la poesía. De esa manera, la influencia modernista con su carácter independiente es identificable, posteriormente, en la poética de la generación del 27.

Esta, al igual que el modernismo, buscó su propia autonomía como instancia expresiva del arte. El lenguaje significó una evidencia de ese período, puesto que resultó más eficaz y asequible para el lector. Fue imprescindible el uso de las figuras retóricas para lograr la explicación contundente de la realidad, ya que a través de ese medio se considerará la subjetividad y conllevará un efecto 
estético. Por ejemplo, se identificaron los tropos de la aliteración y la metáfora. Esta última fue argumentada en función de los planteamientos de Lacan, Quintiliano y Arduini.

El análisis temático se enfocó en la percepción sociopolítica y humana. Esta fue su intención estética. Para el caso de Pedro Salinas, se detectó el tratamiento de lo trascendental, junto con la implicancia del binomio vida-muerte. Se asume que en ese lapso hubo modificaciones en la percepción de la realidad. El compromiso del artista es notable. A la vez, se van incorporando tópicos que logran esa filiación del yo poético con las circunstancias sociales, como su intervención contestataria en la religión, la política, lo bélico y lo subjetivo. De Luis Cernuda, se infirió el abordaje de las vivencias personales y el rol que tuvo desde su libertad frente a la deshumanización. De Federico García Lorca, se reconoció la inclusión de su preocupación por la colectividad; para ello, se explicó la personificación, que facilitó la distinción de la necesidad de expresarse de modo auténtico.

El surrealismo, regido por los postulados psicoanalíticos de Sigmund Freud, fue de utilidad por su misma definición. Esta consistió en basarse en lo sugerente que se suscita desde el inconsciente y lo onírico. Para Octavio Paz, esta modalidad de expresión permite dilucidar la realidad, además de que se extrae la idea de que el autor procura hallar la conjunción individuo-mundo. Asimismo, Paul Illie relaciona este movimiento artístico con lo absurdo y lo no tradicional, que producen la irrupción de los sentidos. Sin embargo, los manifiestos de André Bretón bastarán para cerciorarse de que el objetivo de mostrar un discurso ilógico es para dirigirse con exclusividad a un sector intelectual, en el que prevalece una combinación de ideologías. De esa manera, su aprehensión revelará la pretensión de exponerse mediante la técnica del automatismo psíquico puro, junto con un paradigma revolucionario que está afianzado por la crisis espiritual. En el caso de Luis Cernuda, se apreciará el recurso de la escritura automática. Su empleo consigue retomar mundos posibles, donde se exhibe el rechazo a lo rutinario y la búsqueda de un nuevo orden. Entretanto, Federico García Lorca también partirá de esa misma realidad ficticia, con la finalidad de proponer lineamientos para el desarrollo personal, al igual que recurrirá a la metonimia.

\section{Referencias}

Aleixandre, V. (1935). La destrucción o el amor. Madrid: Signo.

Arduini, S. (2000). Prolegómenos a una teoría general de las figuras. Murcia: Universidad de Murcia.

Aristóteles (1990). Retórica. Trad. de Q. Racionero. Madrid: Gredos.

Bretón, A. (1965). Los manifiestos del surrealismo. Trad., pról. y notas de A. Pellegrini. Buenos Aires: Ediciones Nueva Visión.

Cano Ballesta, J. (1972). La poesía española entre pureza y revolución (1930-1936). Madrid: Editorial Gredos.

Cernuda, L. (1975). Estudios sobre poesía española contemporánea. Madrid: Guadarrama.

Cernuda, L. (1999). Un río, un amor / Los placeres prohibidos. Madrid: Cátedra.

Cernuda, L. (2002). Las nubes / Desalación de la quimera. Barcelona: Cátedra.

Ciplijauskaité, B. (1991). "Transgresión, ruptura y el lenguaje del deseo en los poetas de la generación del 27”. En C. Prestigiacomo \& M. C. Ruta (Coords.), Atti del Convegno dell'Associazione degli Ispanisti Italiani (pp. 29-40). Palermo: Flaccovio Editore.

Fontanier, P. (1977). Les figures du discours. París: Flammarion.

Friedrich, H. (1974). Estructura de la lírica moderna. Barcelona: Seix Barral.

García Lorca, F. (1993a). Romancero gitano. Edición de Mario Hernández. Madrid: Alianza Editorial. 
García Lorca, F. (1993b). Poeta en Nueva York. Edición de Piero Menarini. Madrid: Espasa-Calpe. Guillén, J. (1992). “Apéndice: lenguaje de poema, una generación”. En Lenguaje y poesía (4. a ed.) (pp. 181-197). Madrid: Alianza Editorial.

Guillén, J. (2014). Cántico. Recuperado de https://bit.ly/36K7ZZn

Illie, P. (1982). "El surrealismo español como modalidad”. En V. García de la Concha (Coord.), El surrealismo (pp. 95-103). Madrid: Taurus.

Lacan, J. (1998). El seminario. Libro 5. Las formaciones del inconsciente. Comp. Jacques-Alain Miller. Buenos Aires: Paidós.

Lakoff, G. \& Johnson, M. (1995). Metáforas de la vida cotidiana. Madrid: Cátedra.

Machado, A. (2010). “Juan de Mairena”. En Biblioteca Virtual Universal. http://www.biblioteca. org.ar/libros/155004.pdf

Marichal, J. (1993). Una espléndida década (1926-1936). Cuadernos Hispanoamericanos, 514515, 27-37.

Matas, J., Martínez, J. E. \& Trabado, J. M. (Eds.) (2005). Nostalgia de una patria imposible. Estudios sobre la obra de Luis Cernuda. Madrid: Ediciones Akal.

Paz, O. (1982). "El surrealismo”. En V. García de la Concha (Coord.), El surrealismo (pp. 36-45). Madrid: Taurus.

Quintiliano, M. F. (1887). Instituciones oratorias. Tomo II. Trad. de I. Rodríguez \& P. Sandier. Madrid: Librería de la Viuda de Hernando.

Real Ramos, C. (1990). "El fin de la vanguardia histórica: la tradición como vanguardia en la generación del 27'. En C. Prestigiacomo \& M. C. Ruta (Coords.), Atti del Convegno dell'Associazione degli Ispanisti Italiani (pp. 163-171). Palermo: Flaccovio Editore.

Salinas, P. (2013). La voz a ti debida. https://bit.ly/33vYydk 